\title{
Flora do Parque Nacional do Catimbau, PE, Brasil: Loranthaceae
}

\author{
Gabriella Carla Leite de Vasconcelos ${ }^{1}$ e José Iranildo Miranda de Melo ${ }^{2,3}$
}

Recebido: 13.04.2016; aceito: 9.05.2016

\begin{abstract}
Flora of the Parque Nacional do Catimbau, Pernambuco State, Brazil: Loranthaceae). The family Loranthaceae Juss. is characterized mainly by its hemiparasitic habit. It has high representativeness in the world, occurring, in Brazil, from the humid forests like the Atlantic Rain Forest, to the xeric areas like the Caatinga vegetation. This work presents the taxonomic study of Loranthaceae at the Parque Nacional do Catimbau, semiarid region on Pernambuco state, northeast of Brazil. In the studied area, four species belonging to the genera Psittacanthus and Struthanthus were recorded. Struthanthus confertus Mart. is recorded for the first time to the state of Pernambuco. A key for the separation of species based on morphological descriptions was elaborated. Data on the period of flowering and fruiting and habitat also were provided to the species.

Keywords: Caatinga, hemiparasitic, Psittacanthus, Struthanthus
\end{abstract}

RESUMO - (Flora do Parque Nacional do Catimbau, PE, Brasil: Loranthaceae). A família Loranthaceae Juss. caracteriza-se, principalmente, por apresentar hábito hemiparasítico. Possui alta representatividade mundial; ocorrendo, no Brasil, desde matas mais úmidas como a Mata Atlântica, até áreas xéricas, como a Caatinga. Este trabalho apresenta o estudo taxonômico de Loranthaceae no Parque Nacional do Catimbau (PNC), semiárido do Estado de Pernambuco, Nordeste do Brasil. Na área de estudo, foram registradas quatro espécies pertencentes aos gêneros Psittacanthus e Struthanthus. Struthanthus confertus é registrada pela primeira vez registrada para o Estado de Pernambuco. Foi elaborada uma chave para a separação das espécies baseada nas descrições morfológicas. Também são fornecidos dados sobre o período de floração, frutificação e de habitat para as espécies.

Palavras-chave: Caatinga, hemiparasitas, Psittacanthus, Struthanthus

\section{Introdução}

Loranthaceae Juss., dentre as 18 famílias que compreendem a Ordem Santalales (Nickrent et al. 2010), é uma das mais bem representadas mundialmente (Tainter 2002). A família é caracterizada, principalmente, por seu hábito hemiparasítico e devido a isto têm sua importância econômica associada aos prejuízos que causam a plantações (Cazetta \& Galletti 2003). Ainda assim, destas são extraídos benefícios através do uso medicinal de suas folhas para tratamento de afecções como bronquites e pneumonias (Rodrigues \& Carvalho 2001), além de servirem como bioindicadores, apontando a presença de luminosidade disponível no dossel (Heide-Jorgensen 2008).

Loranthaceae apresenta como principais representantes brasileiras a subtribo Psittacanthinae, amplamente distribuída na América do Sul; encontrada desde matas úmidas a regiões áridas (Vidal-Russell \& Nickrent 2007). Também está representada sobre uma vegetação caracteristicamente xerófita, semiárida, denominada Caatinga, a qual tem seus limites restritos ao território brasileiro e é a proporcionalmente menos estudada entre os Biomas (Leal et al. 2003) devido a crenças infundadas associando o bioma a uma biodiversidade muito baixa (Giulietti et al. 2004). O Parque Nacional do Catimbau (PNC), um remanescente de Caatinga no Estado de Pernambuco, possui uma extrema importância neste contexto por apresentar números relevantes de endemismos e espécies raras (Sampaio et al. 2002).

Este trabalho apresenta o estudo taxonômico da família Loranthaceae no Parque Nacional do

1. Instituto Nacional do Semiárido - INSA, Campina Grande, PB, Brasil

2. Universidade Estadual da Paraíba, Centro de Ciências Biológicas e da Saúde, Departamento de Biologia, Avenida das Baraúnas, 351, Campus Universitário, 58429-500 Campina Grande, PB, Brasil

3. Autor para correspondência: tounerfort@gmail.com 
Catimbau, Pernambuco, de modo a conhecer a composição das espécies desta família na área e ampliar o conhecimento sobre a flora do PNC e da caatinga no Nordeste brasileiro.

\section{Material e métodos}

Área de estudo - O Parque Nacional do Catimbau (PNC), com $62.300 \mathrm{~km}^{2}$, abrange parte dos municípios de Buíque, Ibimirim e Tupanatinga, no Estado de Pernambuco, Nordeste do Brasil (figura 1). Está posicionado na região chamada Sertão do Moxotó (zona de transição entre a Caatinga e o Agreste de Pernambuco). O nome Catimbau advém da serra do Catimbau, localizada no distrito do Catimbau, em Buíque. Grande parte da área física do PNC compreende as movimentações do acidente orográfico conhecido como Chapada de São José, em Buíque. Esta chapada foi formada pelo soerguido de sedimentos cretáceos, depositados sobre depressões tectônicas do escudo cristalino, do Pré-Cambriano, dentro da bacia sedimentar cretácea da série Tucano-Jatobá, na área de drenagem do rio Moxotó (Jacomine et al. 1973). A chapada é formada por serras e morros que constituem relevos testemunhos de uma área contínua de arenitos que ligavam a chapada de São José e as serras do Quiridalho e do Parafuso, em Buíque, mais para Oeste a Serra Negra e do Piriquito, no município de Inajá, e em direção do sudoeste, a Serra de Tacaratu
(Moreira 1977). Estas áreas de arenitos cretáceos e pós-cretáceos medem aproximadamente $160 \mathrm{~km}$ de extensão na direção sudoeste e cerca de $60 \mathrm{~km}$ de largura, além de uma área isolada nas margens do rio Pajeú (Andrade 1954).

Tratamento taxonômico - As análises morfológicas comparativas foram feitas com base em espécimes obtidos no PNC depositados no Herbário João Vasconcelos-Sobrinho (PEUFR), Universidade Federal Rural de Pernambuco (UFRPE). As identificações taxonômicas fundamentaram-se na literatura especializada, principalmente nos estudos de Kuijt (2001, 2009) e Reif \& Andreatta (2011). Em seguida, foram elaboradas descrições taxonômicas e produzida uma chave de identificação para as espécies deste estudo.

As descrições foram baseadas nas terminologias sugeridas por Radford et al. (1974), sendo que para os tipos de venação utilizou-se o trabalho de Hickey et al. (1973). Os tipos de inflorescências foram verificados em Strasburger et al. (1974) e Weberling (1995).

A grafia dos nomes dos autores das espécies de Loranthaceae foi confirmada no "The International Plants Names Index" Online (IPNI 2012). Também foram incluídos dados sobre distribuição, habitats, floração e frutificação para as espécies com base nas informações contidas nas etiquetas das exsicatas examinadas durante esse estudo.
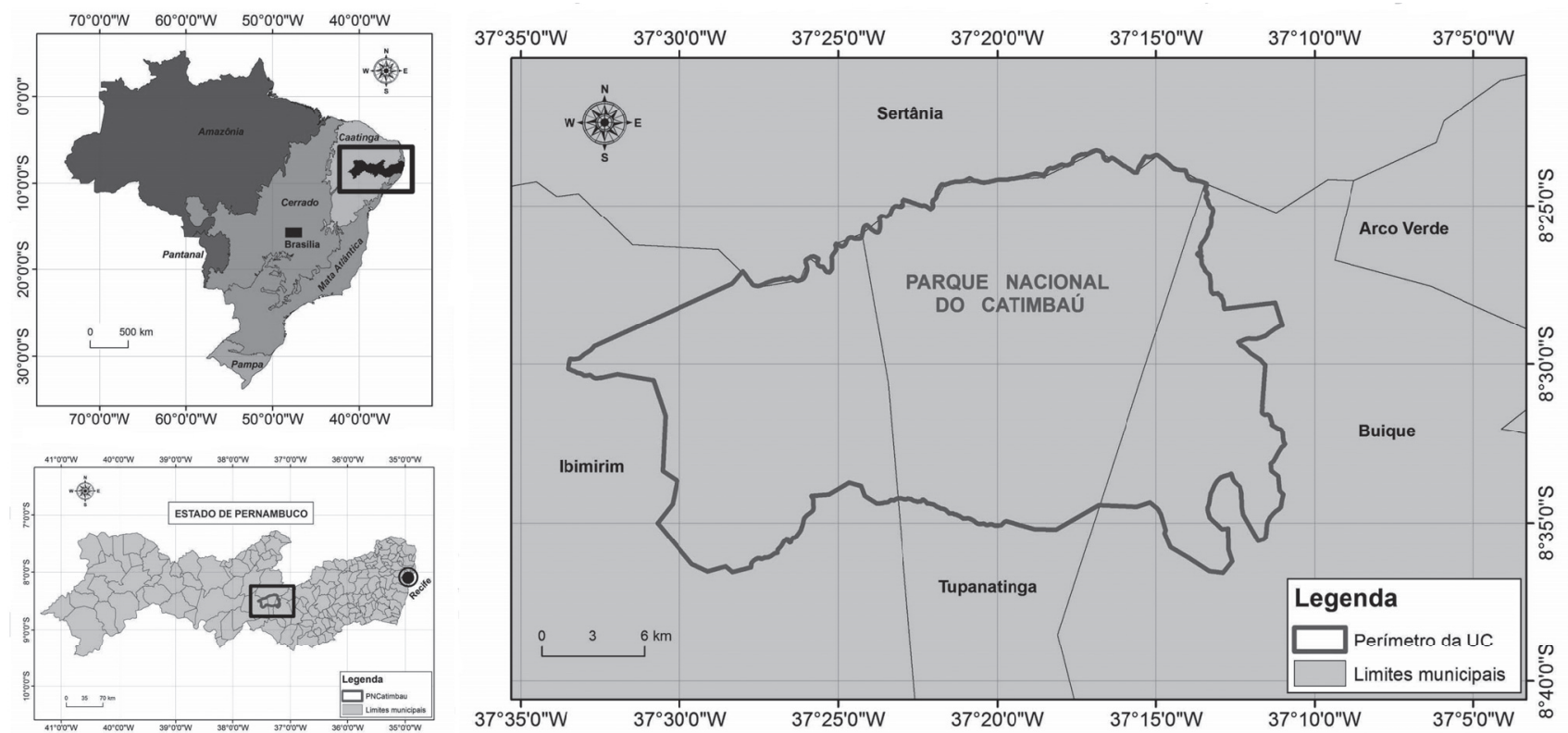

Figura 1. Localização da área de estudo, Parque Nacional do Catimbau (PNC), PE, Brasil.

Figure 1. Location of the studied area, Parque Nacional do Catimbau (PNC), Pernambuco State, Brazil. 


\section{Resultados e Discussão}

Loranthaceae Juss., Ann. Mus. Natl. Hist. Nat. 12: 292.1808 .

Plantas arbustivas, subarbustivas, lianescentes ou eretas, hemiparasitas, de caule quadrangular ou cilíndrico, eretas ou pendentes; raízes epicorticais presentes ou ausentes. Folhas opostas, cruzadas ou dísticas, raramente alternas, opostas a subopostas, simples; venação eucamptódroma a actinódroma. Inflorescências em racemos terminais ou axilares, de díades ou tríades. Flores unissexuadas ou bissexuadas (Struthathus), hexâmeras, subentendidas por brácteas ou não, estames isostêmones, epipétalos, estigma e estilete único. Bagas de mesocarpo viscoso, 2 ou mais cotilédones, monospérmicas.

A família reúne 73 gêneros distribuídos nas regiões tropicais e subtropicais de todo o globo, com algumas espécies ocorrendo em regiões temperadas (Nickrent et al. 2010). No Brasil ocorrem 129 espécies em 12 gêneros, com 68 espécies endêmicas (Dettke \& Caires 2015). No PNC foram registradas quatro espécies em dois gêneros: Psittacanthus e Struthanthus.

Chave para as espécies de Loranthaceae do PNC

1. Ausência de raízes epicorticais; lenticelas geralmente ausentes nos caules ou, quando presentes, esparsadas; flores vistosas, $>4 \mathrm{~cm}$ compr., pediceladas ........ 1. Psittacanthus cordatus

1. Presença de raízes epicorticais; caules densamente lenticelados; flores pequenas, $<4 \mathrm{~cm}$ compr., sésseis

2. Plantas de caules estriados; tríades dispostas em glomérulos 2. Struthanthus confertus

2. Plantas de caules lenticelados; tríades nunca dispostas em glomérulos

3. Lâmina foliar com ápice agudo a acuminado; inflorescência com bráctea mediana proeminente em relação às laterais ...... 4. Struthanthus syringifolius

3. Lâmina foliar com ápice emarginado a cuspidado; inflorescência com bráctea mediana semelhante às laterais

\section{Struthanthus polyrhizus}

Psittacanthus Mart. Tipo: Psittacanthus americanus (L.) Mart., Flora 13: 108. 1830.

Este gênero reúne 119 espécies distribuídas do México à Argentina (Kuijt 2009). Dettke \& Caires
(2015) registraram 42 espécies de Psittacanthus para a flora brasileira. No PNC está representado por uma espécie.

1. Psittacanthus cordatus (Hoffmanns.) G. Don, Gen. Hist. 3: 416. 1834.

Figura $2 \mathrm{a}-\mathrm{b}$

Hemiparasitas eretas, pouco ramificadas e pouco folhosas. Raízes epicorticais ausentes. Caule marrom acinzentado, cilíndrico, com lenticelas esparsas, entrenós 2-6 $\times 0,3-0,5 \mathrm{~cm}$. Folhas opostas cruzadas, verde pálido, glabras, crassas, sésseis; lâmina 4,5-6 $\times 2-3 \mathrm{~cm}$, oblonga, base cordada, ápice obtuso a arredondado; venação actinódroma. Inflorescências em racemos de tríades na porção terminal, $6 \mathrm{~cm}$ compr., 2-4 pares de tríades por inflorescência, pedúnculos com ca. $1 \mathrm{~cm}$ compr., ramos da inflorescência cilíndricos; bráctea-1, basal. Flores pediceladas; pedicelo 0,7-1 × 0,1-0,2 cm; botões cilíndricos; calículo íntegro na base em forma de bainha, alaranjado; corola com 6 pétalas, $4-5(-6) \times 0,2 \mathrm{~cm}$, laranja intenso; estames 6 , epipétalos, 3 maiores com $4,7 \times 0,1 \mathrm{~cm}, 3$ menores com 4,3 $\times 0,1 \mathrm{~cm}$, anteras inclusas; ovário $0,3 \times 0,2 \mathrm{~mm}$, côncavo. Frutos não observados.

Material examinado: BRASIL. Pernambuco: Buíque, Fazenda Laranjeiras, 20-VIII-1994 (fl.), M.J.N. Rodal 316 (PEUFR); ibidem, Fazenda Laranjeiras, 0837'S, 37¹0'W, 790 m, 19-V-1995 (fl.), E. Inácio et al. 50 (PEUFR); ibidem, Fazenda Laranjeiras, $08^{\circ} 37^{\prime} \mathrm{S}-37^{\circ} 10^{\prime} \mathrm{W}, 790 \mathrm{~m}, 16-\mathrm{VI}-1995$ (fl.), L. Figueiredo et al. 95 (PEUFR).

No Brasil ocorre nos Estados de Rondônia, Amazonas, Pará, Tocantins, Piauí, Ceará, Paraíba, Pernambuco, Alagoas, Sergipe, Bahia, Goiás, Mato Grosso do Sul, Mato Grosso, Minas Gerais, Rio de Janeiro e São Paulo (Dettke \& Caires 2015) e na Paraíba (Vasconcelos \& Melo 2015).

Psittacanthus cordatus caracteriza-semorfologicamente pela lâmina foliar de ápice obtuso a arredondado e 2-4 pares de tríades por inflorescência. Encontrada florida em maio, junho e agosto. De acordo com Kuijt (2009), seus frutos são elipsoides com dois cotilédones.

Ilustrações desta espécie podem ser encontradas em Kuijt (2009; p. 122, fig. 49).

\section{Struthanthus Mart.}

Hemiparasitas glabras, escandentes. Raízes epicorticais presentes ao longo do caule, entre os 

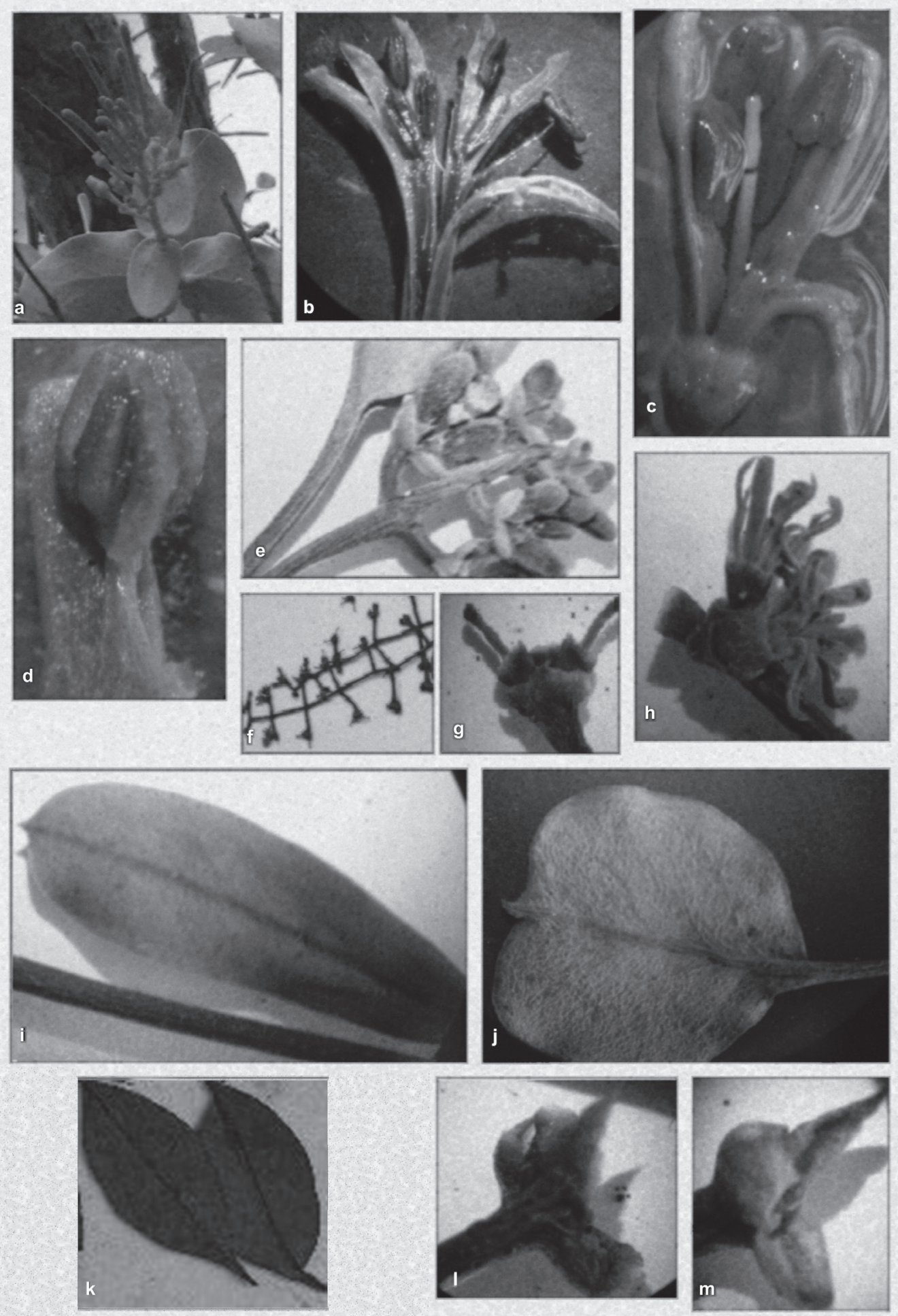

Figura 2. Espécies de Loranthaceae encontradas no Parque Nacional do Catimbau (PNC), PE, Brasil. Psittacanthus cordatus: a. Inflorescência. b. Flor. Struthanthus confertus: c. Flor. d. Antera, evidenciando sua inserção. e. Inflorescência, evidenciando a bráctea. Struthanthus polyrhizus: f. Disposição da inflorescência. g. Flores em tríades. h. Flores. i. Lâmina foliar. j. Folha. Struthanthus syringifolius. k. Folhas. 1-m. Bráctea mediana. (Fotografias: G.C.L. Vasconcelos).

Figure 2. Loranthaceae species found at Parque Nacional do Catimbau (PNC), Pernambuco State, Brazil. Psittacanthus cordatus. a. Inflorescence. b. Flower. Struthanthus confertus. c. Flower. d. Anther, showing its insertion. e. Inflorescence showing the bract. Struthanthus polyrhizus. f. Inflorescence arrangement. g. Flowers in triads. h. Flowers. i. Leaf blade. j. Leaf. Struthanthus syringifolius. k. Leaves. 1-m. Middle bract. (Photos: G.C.L. Vasconcelos). 
entrenós ou na base dos ramos da planta. Caule geralmente lenticelado, quando jovem cilíndrico ou angular, quando adulto cilíndrico. Folhas opostas ou subopostas. Inflorescências geralmente em racemos de tríades, axilares ou terminais em racemos, espigas, corimbos ou glomérulos. Flores 1-1,5 cm compr., geralmente sésseis; corola com depressões que acomodam as anteras; flores masculinas com estames dimórficos, anteras dorsifixas e versáteis; flores femininas com glândulas nectaríferas circundando o gineceu, apresentando estames e anteras atrofiadas, desprovidas de depressões nos filetes que acomodam as anteras. Fruto baga com endosperma, 2-cotiledonar.

Reúne 45 espécies distribuídas na região neotropical (Kuijt 2013). No PNC, o gênero Struthanthus está representado por três espécies.

2. Struthanthus confertus (Mart.) Mart., Flora 13: 104. 1830.

Figura 2c-e

Hemiparasitas pouco ramificadas e bastante folhosas. Raízes não observadas. Caule marrom, glabro, com estrias em toda sua extensão, cilíndrico, entrenós (2,5-)3-5,5 × 0,2-0,4(-0,6) cm. Folhas opostas cruzadas, glabras, pecioladas; pecíolo 0,7-1 × 0,2 cm; lâmina 4,5-5(-7) × 3-4 cm, ovada a cordiforme, base obtusa e ápice acuminado a cuspidado; venação eucamptódroma com a nervura central abaxialmente proeminente. Inflorescências em glomérulos de tríades apicais, ramos compressos, $0,7 \times 0,2 \mathrm{~cm}$, sésseis, 4-6(-8) pares de tríades dispostas em glomérulos, dióicas, geralmente 1 por axila. Flores sésseis; botões claviformes; bractéolas agudas, calículo integro em bainha; corola com 6 pétalas, $0,5 \times 0,1 \mathrm{~cm}$, avermelhada; estames 6 , epipétalos, dimórficos, 3 maiores com $0,5 \mathrm{~cm}$ compr., 3 menores com $0,3 \mathrm{~cm}$ compr., alternos, anteras dorsifixas; ovário $0,4 \times 0,2 \mathrm{~mm}$, côncavo. Baga 0,5-0,7 $\times 0,4 \mathrm{~cm}$, ovoide, enegrecida, glabrescente.

Material examinado: BRASIL. Pernambuco: Buíque, Fazenda Laranjeiras, $08^{\circ} 30^{\prime} \mathrm{S}-37^{\circ} 13^{\prime} \mathrm{W}, 799$ m, 5-IX1995 (fl.), A. Laurênio et al. 126 (PEUFR); ibidem, estrada Buíque-Catimbau, $08^{\circ} 30^{\prime} \mathrm{S}-37^{\circ} 15^{\prime} \mathrm{W}, 799 \mathrm{~m}$, 8-X-1995 (fl.), L.S. Figueirêdo et al. 208 (PEUFR); ibidem, estrada Buíque-Catimbau, sobre Piptadenia obliqua, 9-X-1995 (est.), L. Figueirêdo et al. 225 (PEUFR); ibidem, estrada Buíque-Catimbau, $08^{\circ} 37^{\prime} \mathrm{S}-37^{\circ} 10^{\prime} \mathrm{W}, 799$ m, 23-II-1996 (fr.), K. Andrade et al. 312 (PEUFR); ibidem, estrada Buíque-Catimbau, 8-III-1996 (fr.), M. Tschá et al. 645 (PEUFR); ibidem,

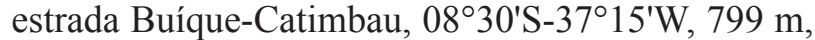
8-VI-1996 (fl., fr.), E. Freire et al. 102 (PEUFR).

No Brasil, ocorre nos Estados da Bahia, Goiás, Espírito Santo, Minas Gerais e Rio de Janeiro e no Distrito Federal (Dettke \& Caires 2015).

Caracteriza-se, principalmente, pela presença de estrias ao longo do caule e pelas folhas de lâmina diminuta, de ápice acuminado a cuspidado, conferindo aspecto ovado a peltado-cordiforme ou, ainda, pelas tríades em glomérulos. Até o momento, Struthanthus confertus não havia sido registrada para Pernambuco constituindo, neste trabalho, um novo registro para o Estado. Encontrada florida em junho, setembro e outubro e frutificada em fevereiro, março e junho.

3. Struthanthus polyrhizus (Mart.) Mart., Flora 13: 105. 1830.

Figura 2f-j

Hemiparasitas decumbentes, bastante ramificadas, pouco folhosas. Raízes epicorticais na base da planta e ao longo dos entrenós. Caule acinzentado, densamente lenticelado, quando jovem anguloso, cilíndrico quando adulto; entrenós 5-7(-9) × 0,2 cm compr. Folhas semi-coriáceas, opostas a subopostas, verdeescuro, glabras, pecioladas; pecíolo 0,5-1-2 × 0,1 cm; lâmina 3-6 × 1,5-3 cm, obovada, base estreita a aguda, ápice emarginado a cuspidado, similar a um coração, mucronado; venação eucamptódroma, nervura central proeminente na face abaxial. Inflorescências em corimbos sésseis de tríades, ramos angulosos, 1 por axila, 4-5 cm compr., 3-4 pares de tríades, pedunculadas; pedúnculo $0,5 \mathrm{~cm}$ compr.; bráctea mediana semelhante às laterais. Flores sésseis; unissexuadas, bracteadas; botões cilíndricos; calículo íntegro na forma de bainha, verde; corola com 6 pétalas, $0,3-0,5 \times 0,1 \mathrm{~cm}$, creme a avermelhada; flores masculinas com 6 estames, epipétalos, dimórficos, 3 maiores com $0,5 \times 0,1 \mathrm{~cm}, 3$ menores com $0,3 \times 0,1 \mathrm{~cm}$, alternos, anteras cordadas, apiculadas, dorsifixas, inclusas; flores femininas de ovário côncavo; estilete cilíndrico 0,3-0,4 cm compr.; estaminóides filiformes, com tecas compressas. Baga $0,8 \times 0,4 \mathrm{~cm}$, elíptica, avermelhada, glabra

Material examinado: BRASIL. Pernambuco: Buíque, Serra do Catimbau, $08^{\circ} 37^{\prime} \mathrm{S}-37^{\circ} 15^{\prime} \mathrm{W}, 790 \mathrm{~m}$, 16-IX-1994 (fl., fr.), M.F. Sales 376 (PEUFR); ibidem, estrada Buíque-Catimbau, $08^{\circ} 37^{\prime} \mathrm{S}-37^{\circ} 10^{\prime} \mathrm{W}$, 790 m, 18-V-1995 (fl.), K. Andrade et al. 40 (PEUFR); ibidem, estrada Ibimirim-Petrolândia, 19-VII-1995 (fl.), M.F. Sales et al. 632 (PEUFR); ibidem, $08^{\circ} 37^{\prime} \mathrm{S}-37^{\circ} 15^{\prime} \mathrm{W}, 08^{\circ} 30^{\prime} \mathrm{S}-37^{\circ} 15^{\prime} \mathrm{W}, 799 \mathrm{~m}$, 
17-VIII-1995 (fl.), L. Figueiredo et al. 145 (PEUFR); ibidem, 08 $37^{\prime} \mathrm{S}-37^{\circ} 10^{\prime} \mathrm{W}, 790$ m, 17-X-1994 (fl., fr.), M.B. Costa e Silva 254 (PEUFR); ibidem, 11-I1996 (fl.), K. Andrade et al. 275 (PEUFR); ibidem, 23-II-1996 (fl.), E. Freire et al. 48 (PEUFR); Ibimirim, estrada Ibimirim-Petrolândia, 10-III-1995 (fl.), M.F. Sales et al. 569 (PEUFR); ibidem, estrada IbimirimPetrolândia, 19-VII-1995 (fl.), M.F. Sales et al. 632 (PEUFR).

No Brasil, ocorre nos Estados do Piauí, Pernambuco, Alagoas, Sergipe, Bahia, Minas Gerais, Espírito Santo, Rio de Janeiro, São Paulo, Paraná, Santa Catarina e Rio Grande do Sul (Dettke \& Caires 2015) e na Paraíba (Vasconcelos \& Melo, 2015).

Caracteriza-se, especialmente, pelo caule densamente lenticelado. No hospedeiro, tende a ocupar inteiramente a sua copa, lançando diversos ramos originários de um mesmo indivíduo. Morfologicamente, S. polyrhizus pode ser facilmente reconhecível pelas folhas de formato diferenciado devido ao ápice emarginado a cuspidado, similar a um coração, com a sua base constituindo o pecíolo. Encontrada florida em janeiro, fevereiro, março, maio, julho, agosto, setembro e outubro e frutificada em setembro e outubro.

4. Struthanthus syringifolius (Mart.) Mart., Flora 13(1): 105. 1830.

Figura 2k-m

Hemiparasitas eretas, pouco ramificadas, pouco folhosas, ramos apicais decumbentes. Raízes epicorticais encontradas apenas na base da planta. Caule marrom, lenticelado, quando jovem achatado, adulto cilíndrico, entrenós 4,5-5 ×0,4 cm. Folhas semicoriáceas, opostas cruzadas, raramente subalternas, verde-amareladas, glabras, pecioladas; pecíolo 1,5-2 × 0,1-0,2 cm; lâmina (4-)6,5-7 × 2,5-3 cm, oblongo-lanceolada, base obtusa a cuneada, ápice agudo a acuminado; venação eucamptódroma na face adaxial, nervura central proeminente na face abaxial. Inflorescências em racemos de tríades aglomeradas na porção terminal dos ramos, ramos compressos, tetrágonos, 1 por axila, 6-7 cm compr., com 3-4 pares de tríades, pedúnculos 2-4 mm compr.; bráctea mediana proeminente em relação às laterais. Flores sésseis; brácteas agudo-denteadas, a mediana mais proeminente; botões claviformes; calículo íntegro na forma de bainha, verde; corola com 6 pétalas, 0,4-0,5 × 0,1-0,2 cm, esverdeada; estames 6 , epipétalos, dimórficos, 3 maiores com $0,6 \times 0,1 \mathrm{~cm}, 3$ menores com $0,4 \times 0,1 \mathrm{~cm}$, alternos, anteras 4-tecas, dorsifixas, inclusas; ovário $0,1 \times 0,2 \mathrm{~cm}$, côncavo. Baga 1,2-1,5 × 0,7-0,9 cm, elíptica, amarela a alaranjada, glabra.

Material examinado: BRASIL. Pernambuco: Buíque, Fazenda Laranjeiras, $08^{\circ} 37^{\prime} \mathrm{S}-37^{\circ} 10^{\prime} \mathrm{W}, 799 \mathrm{~m}$, 20-VIII-1994 (fl.), M.J.N. Rodal 322 (PEUFR); ibidem, estrada Buíque-Catimbau, $08^{\circ} 30^{\prime} \mathrm{S}-37^{\circ} 15^{\prime} \mathrm{W}$, 799 m, 10-X-1995 (fl.), L. Figueiredo et al. 238 (PEUFR); ibidem, Sitio Pititi, 31-I-1998 (fr.), A. Laurênio et al. 689 (PEUFR).

Para o Brasil, foi registrada nos Estados do Acre, Amazonas, Ceará, Paraíba, Pernambuco, Alagoas, Sergipe, Bahia, Goiás, Mato Grosso, Minas Gerais, Espírito Santo e Rio de Janeiro (Dettke \& Caires 2015).

A espécie Struthanthus syringifolius é reconhecível, principalmente, pela bráctea mediana proeminente em relação às brácteas laterais, além da semelhança de suas folhas com espécies do gênero Syringa L. (Oleaceae), origem do seu epíteto específico. Encontrada florida em agosto e outubro e frutificada em janeiro.

\section{Conclusão}

Os gêneros registrados na área de estudo (Psittacanthus e Struthanthus) podem ser diferenciados com base, principalmente, na presença ou não de raízes epicorticais; Psittacanthus cordatus não apresenta raízes epicorticais, possui ramos mais eretos e flores de cores vibrantes, enquanto Struthanthus possui raízes epicorticais, e seus ramos, mesmo quando eretos, apresentam-se mais pêndulos que aqueles encontrados em Psittacanthus, com flores de cores geralmente discretas. Todas as espécies de Loranthaceae registradas no Parque Nacional do Catimbau (PNC) apresentam-se amplamente distribuídas no Brasil, sendo acrescentada para Pernambuco a distribuição de Struthanthus confertus, que nesse trabalho constitui um novo registro para a flora do Estado.

\section{Agradecimentos}

À Dra. Maria Elisabeth Bandeira Pedrosa, curadora do Herbário João Vasconcelos-Sobrinho (PEUFR), pelo empréstimo das coleções para realização deste trabalho, e à Dra. Margareth Ferreira de Sales (UFRPE), coordenadora do Projeto "Flora do Parque Nacional do Catimbau, Pernambuco, Brasil" pelo convite para participar do mesmo. 
J.I.M. Melo agradece ao Conselho Nacional de Desenvolvimento Científico e Científico (CNPq) a Bolsa de Produtividade em Pesquisa (Proc. $\mathrm{n}^{\circ}$. 302751/2012-2 (PQ -2)).

\section{Literatura citada}

Andrade, G.O. 1954. A Serra Negra - Uma relíquia geomorfológica e higrófita nos tabuleiros pernambucanos. Imprensa Oficial, Recife.

Cazetta, E. \& Galetti, M. 2003. Ecologia das ervas-depassarinho. Ciência Hoje 3: 72-74.

Dettke, G.A. \& Caires, C.S. 2015. Loranthaceae. In: Lista de Espécies da Flora do Brasil. Jardim Botânico do Rio de Janeiro, Rio de Janeiro. Disponível em http:// floradobrasil.jbrj.gov.br/jabot/floradobrasil/FB152 (acesso em 9-IX-2015).

Giulietti, A.M., Bocage Neta, A.L., Castro, A.A.J.F., Gamarra-Rojas, C.F.L., Sampaio, E.V.S.B., Virgínio, J.F., Queiroz, L.P., Figueiredo, M.A., Rodal, M.J.N., Barbosa, M.R.V. \& Harley, R.M. 2004. Diagnóstico da vegetação nativa do bioma da caatinga. In: J.M.C. Silva, M. Tabarelli, M.T. Fonseca \& M.V. Lins (eds.). Biodiversidade da Caatinga: áreas e ações prioritárias para a conservação. Ministério do Meio AmbienteUniversidade Federal de Pernambuco, Brasília, pp. 47-90.

Heide-Jorgensen, H.S. 2008. Parasitic Flowering Plants. Koninklijke Brill NV, Leiden.

Hickey, L.J. 1973. Classification of the architecture of dicotyledonous leaves. American Journal of Botany 60: 17-33.

IPNI - International Plant Names Index. 2012. The International Plants Names Index. Disponível em http:// www.ipni.org/index.html (acesso em 29-VIII-2014).

Jacomine, P.K.T., Cavalcanti, A.C., Burgos, N., Pessoa, S.C.P. \& Silveira, C.O. 1973. Levantamento exploratório - reconhecimento de solos do Estado de Pernambuco: descrição de perfis de solos e análises. V. 1, SUDENE, Recife, pp. 1-175 (Boletim Técnico, n. 26).

Kuijt, J. 2001. Loranthaceae. In: P. Berry, B. Holst \& K. Yatskievych (eds.). Flora of the Venezuelan Guayana. Missouri Botanical Garden, Saint Louis, v. 6, pp. 37-59.

Kuijt, J. 2009. Psittacanthus (Loranthaceae). Systematic Botany Monographs, Saint Louis, v. 86, pp. 1-361.
Kuijt, J. 2013. A brief taxonomic history of Neotropical mistletoe genera, with a key to the genera. Blumea 58: 263-266.

Leal, I.R., Tabarelli, M. \& Silva, J.M.C. (eds.). 2003. Ecologia e Conservação da Caatinga. Editora Universitária, Universidade Federal de Pernambuco, Recife.

Moreira, A.A.N. 1977. Relevo. In: Instituto Brasileiro de Geografia e Estatística (ed.). Geografia do Brasil Região Nordeste. Instituto Brasileiro de Geografia e Estatística, Rio de Janeiro, pp. 1-45.

Nickrent, D.L., Malecót, V., Vidal-Russel, R. \& Der, J.P. 2010. A revised classification of Santalales. Taxon 59: 538-558.

Radford, A.E., Dickison, W.C., Massey, J.R. \& Bell, C.R. 1974. Vascular Plant Systematics. Harper Collins, New York.

Reif, C. \& Andreata, R.H.P. 2011. Contribuição à taxonomia de Loranthaceae no Estado do Rio de Janeiro, Brasil. Pesquisas, Botânica, 62: 71-115.

Rodrigues, V.E.G. \& Carvalho, D.A. 2001. Levantamento etnobotânico de plantas medicinais no domínio do cerrado na região do alto Rio Grande - Minas Gerais. Ciência \& Agrotecnologia 25: 102-123.

Sampaio, E.V.S.B., Giulietti, A.M., Virgínio, J. \& Gamarra-Rojas, C. (orgs.). 2002. Vegetação e Flora da Caatinga. Associação Plantas do Nordeste (APNE) e Centro Nordestino de Informações sobre Plantas (CNIP), Recife.

Strasburger, E.A., Noll, F. \& Rudolf, J. 1974. Tratado de Botánica. Editorial Marín, Barcelona.

Tainter, F.H. 2002. What does mistletoes have to do with Christmas? Feature Story. The American Phytopathological Society, St. Paul. Disponível em http://www.apsnet.org/online/feature/mistletoes (acesso em 14-IX-2015).

Vasconcelos, G.C.L. \& Melo, J.I.M. 2015. Flora of the State of Paraíba, Brazil: Loranthaceae Juss. Acta Scientiarum, Biological Sciences 37: 239-250.

Vidal-Russell, R. \& Nickrent, D.L. 2007. The Biogeographic History of Loranthaceae. Darwiniana 45: 34-54.

Weberling, F. 1995. Morphology of flowers and inflorescences. Cambridge University Press, Cambridge. 